\title{
Scanning Electron Microscopic Observations on the Early Development of the Spinal Ganglia in Salamander Larvae
}

\author{
By \\ Shigeki HIRANO ${ }^{1)}$ and Toshio SHIRAI ${ }^{21}$
}

1) Department of Anatomy, Niigata University School of Medicine.

2) Department of Anatomy, Yamagata University School of Medicine.

\begin{abstract}
Summary: It was observed by a scanning electron microscopy that the migration and aggregation process of the neural crest cells to form the spinal ganglia in the space between the neural tube and the somites in salamander larvae.

When the neural crest cells began to migrate, they projected their thick cytoplasmic processes along the dorse-lateral wall of the neural tube. Completing their migration in the space between the neural tube and the somites, the neural crest cells changed their shape to flattend polygonal and formed a sheet in this space. After the migration of the neural crest cells the sclerotome cells invaded into this space from the ventral area upward. At that time the cell sheet formed by the neural crest cells was segmentally divided corresponding to the somites. Thereafter a thick cell layer was formed by the neural crest cells and the sclerotome cells. But the distribution pattern of each cell in this layer could not be recognized. Subsequently the cell group formed the spinal ganglion appeared the metameric arrangement in this layer. Finally each cell group became the compact cell mass as the spinal ganglion.

These findings showed that in hynobius larvae the neural crest cells developed into a spinal ganglion may have the unspecified migrated pathway from the neural crest to the site of the spinal ganglion and aggregate through the period of the cell sheet.
\end{abstract}

Spinal gangila are composed of the neural crest cells migrated into the space between the neural tube and the somites (Raven, 1935). Also, it has been shown by Lehmann (1927) and Detwiler (1937) that the segmental arrangement of the mesodermal tissues induced the same arrangement of the spinal ganglia and the development of neurons from the migrated neural crest cells in the spinal ganglia. It seems to be interesting to observe how the neural crest cells migrate from the neural crest on the dorsal wall of the neural tube into the space between the neural tube and the somites and the migrated cells aggregate to form the spinal ganglia.
Scanning electron microscope is one of the suitable methods to investigate this process. In the past there have been some scanning electron microscopic observations on the neural crest cells in the neural crest and during their early migration period (Bancroft and Bellairs, 1976 ; Löfberg and Ahlfors, 1979; Löfberg et al., 1980; Tosney, 1978 and 1982; Erickson and Weston, 1983; Hirano and Shirai, 1984; Spieth and Keller, 1984), and on the developmental changes of these cells in the spinal ganglion (Matsuda and Uehara, 1984), but the process of a spinal ganglion formation has almost not been observed by scanning electron microscopy. Because it is difficult to distinguish

This paper is dedicated to Professor Emeritus Kazuyo Shimai in commemoration of his 65 th birthday 
the neural crest cells from the sclerotome cells after these cells mixed together in the space between the neural tube and the somites.

The present study was continuously observed on the neural crest cells from their migration to the spinal ganglion formation. In addition, to distinguish the neural crest cells during the formation of the spinal ganglion from the sclerotome cells, the sclerotome cells were also observed at the same time in the same specimens prepared as follows.

\section{Materials and Methods}

Larvae of salamander (Hynobius lichenatus Boulenger) at stages 30-45 (according to Sawano, 1947) were used.

As it was necessary to distinguish the neural crest cells from the sclerotome cells in the space between the neural tube and the somites, the speciments repared as follows were observed by a scanning electron microscope. A larva was fixed in $2.5 \%$ glutaraldehyde in $0.1 \mathrm{M}$ phosphate buffer ( $\mathrm{pH} 7.4$ ) and postfixed with $1 \%$ osmic acid in the same buffer. After fixation, the larva was dehydrated by ethyl alcohol series, immersed in isoamyl acetate and dried at the critical point, and then the belly of the larva was attached on the metal block with adhesive paste. After adhesion, the adhesive paste was spread on the dorsal skin. When this paste was half-dried, the margin of the paste was carefully picked by forceps. With this procedure the dorsal skin was removed with adhesive paste. Thenafter the adhesive paste was again spread on the dorsal surface of the somites. At the adhesive paste halfdried, the somites were carefully removed from the larva with forceps or steel needles. Gold coating was done and the medial surface of the somites and the lateral surface of the neural tube in the same space of the anterior area of the trunk were complementary ob- served.

\section{Results}

When the neural creast cells began to migrate at stage 30 , they projected their cytoplasmic processes on the lateral surface of the neural tube at first (Fig.1-a). After the neural crest cells migrated in the area between the neural tube and the somites, they became flattened polygonal in shape and contacted with each other (Fig. 2-a). These changes advanced along craniocaudal direction. A segmental distribution of the neural crest cells could not be recognized. At this stage the sclerotome cells moved upward, but they did not contact with the neural crest cells yet (Fig. 2-a). Their migration pathway corresponded with a somite. Shortly the neural crest cells and the sclerotome cells were in contact with each other, and two cell groups were shown the metamerism corresponding to the somites (Fig. $3-b)$. One dorsal cell group was formed by smaller sized cells and seemed as if these cells were enclosed by other cells migrated from the ventral area. The former cells were probably the neural crest cells and the latter the sclerotome cells. But the segmental arrangement of two cell groups was soon lost and the thick cell layer was formed by these cells (Fig. 4).

At a later stage (st. 36) the cell masses of the spinal ganglia appeared as the shape of an inverted triangle (Fig. 5), but it was difficult to distinguish the cells in the triangle from their surrounding cells with their shape and size (Fig. 5-b). The shape of each cell in the cell mass was polygonal and their arrangement was relatively loose (Fig. 5-b). The spinal ganglion became more and more compact and the surface of it showed smooth (Figs. 6 and 7), and the developing vertebral arches were appeared between the spinal ganglia (Fig. 7). 


\section{Discussion}

There are many reports on the migration of the neural crest cells in the space between the neural tube and the somites. Erickson and Weston (1983) showed in mouse embryo that the distribution of the neural crest cells in this space was uniform and these cells formed a continuous sheet. In a chick embryo Weston (1963) reported that after the inversion of the neural crest cells in this space they migrated ventrally through the segmental pathway corresponding to somites and formed of the spinal ganglia. However, Thiery et al. (1982), and Vincent and Thiery (1984) showed in a chick embryo that the neural crest cells in the intersomitic space migrated to the ventral area of the notochord and their cells placed in the space between the neural tube and the bulk of the somite formed the spinal ganglion. Their findings seem to suppose that the neural crest cells continue craniocaudally as the cell sheet at the medial surface of the somite.

In urodelen larvae Detwiler (1937) investigated the distribution of the neural crest cells and the sclerotome cells in the space between the neural tube and the somites in Amblystoma, and showed that the distribution of the neural crest cells was uniform at the early period of these migration, but the site of their distribution and the pathway from it to the spinal ganglion could almost not be known from his findings because the relationship between the migrating neural crest cells and the somite was not described. In the hynobus larvae the neural crest cells began to migrate directly into the space between the neural tube and the somites, and they spread without taking the metameric arrangement. These findings suggest that the neural crest cells of the hynobius larvae may have the unspecified pathway to the spinal ganglion during their migration and form the cell sheet in the space between the neural tube and the somites after their migration, and subsequently divide segmentally to form of the spinal ganglia.

The neural crest cells migrated to the ventral area and formed the autonomic nervous system were observed in Amblystoma (Detwiler, 1937; Vogel and Model, 1977), but in the present study these cells could not be found.

\section{References}

1) Bancroft, M. and Bellairs, R: The neural crest cells of the trunk region of the chick embryo studied by SEM and TEM. Zoon, 4: 73-85, 1976

2) Detiler S.R.: Observations upon the migration of neural crest cells, and upon the development of the spinal ganglia and vertebral arches in Amblystoma. Am. J. Anat., 61: 63-94, 1937

3) Erickson, C.A. and Weston, J.A.: An SEM analysis of neural crest migration in the mouse. J. Embryol. exp. Morph., 74: 97-118, 1983

4) Hirano, S. and Shirai, T.: Morphogenetic studies on the neural crest of Hynobius larvae using vital staining and India ink labeling methods. Arch. histol. jap., 47: 57-70, 1984

5) Lehmann, F.E.: Further studies on the morphogenetic role of the somites in the development of the nervous system of amphibians. The differentiation and arrangement of the spinal ganglia in Pleurodeles walti. J. Exp. Zool., 49: 93-131, 1927

6) Löfberg, J. and Ahlfors, K.: Extracellular matrix organization and early neural crest cell migration in the Axolotl embryo. Zoon, 6: $87-101,1978$

7) Löfberg, J., Ahlfors, K. and Fällström, C.: Neural crest cell migration in relation to extracellular matrix organization in the embryonic Axolotl trunk. Dev. Biol., 75: 148-167, 1980

8) Matsuda, S. and Uehara, Y.: Prenatal development of the rat dorsal root ganglia. A scanning electron-microscopic study. Cell Tissue Res., 235: 13-18, 1984

9) Raven, C.P.: Zur Entwicklung der Ganglienleiste. V. Über die Differenzierung des Rumpfganglienleistenmaterials. Roux'Arch. Entwicklungsmech., 134: 122-146, 1935 
10) Sawano, J.: Normal table of Hynobius lichenatus Boulenger. Gurusu Bunko, Sapporo (1947) (in Japanese)

11) Spieth, J. and Keller, R.E.: Neural crest cell behavior in white and dark larvae of Ambly. stoma mexicanum: Differences in cell morphology, arrangement, and extracellular matrix as related to migration. J. Exp. Zool., 229: 91-107, 1984

12) Thiery, J.P., Duband, J.L. and Delouvée, A: Pathways and mechanisms of avian trunk neural crest cell migration and localization. Dev. Biol., 93: 324-343, 1982

13) Tosney, K.W.: The early migration of neural crest cell in the trunk region of the avian embryo: An electron microscopic study. Dev. Biol., 62: 317-333, 1978
14) Tosney, K.W.: The segregation and early migration of cranial neural crest cells in the avian embryo. Dev. Biol., 89: 13-24, 1982

15) Vincent, M. and Thiery, J.P.: A cell surface marker for neural crest and placodal cells: Further evolution in peripheral and central nervous system. Dev. Biol., 103: 468-481, 1984

16) Vogel, D.L. and Model, F.G.: Development of the sympathetic system in the mexican axolotl. Amblystoma mexicanun. Dev. Biol., 56: 76-96, 1977

17) Weston, J.A. A radioautographic analysis of the migration and localization of trunk neural crest cells in the chick. Dev. Biol., 6: $297-310,1963$ 


\section{PLATES}




\section{Explanation of Figures}

\section{Plate I}

Fig. 1. A pair of scanning electron micrographs showing the lateral surface of the neural tube(a) and the medial surface of the somites(b) facing it at the on set of the neural crest cell migration. Star indicates the cranial side, and arrow the dorsoventral direction. NT: the lateral surface of the neural tube, C: the lateral surface of the notochord, $\mathrm{C}^{\prime}$ and $\mathrm{NT}^{\prime}$ : the medial surface of the somites, NT faced $\mathrm{NT}^{\prime}$ and $\mathrm{C}$ faced C', NT and NT 'form a space between the neural tube and the somites. These symbols and orientation are the same in the following paired figures. a: A large number of the cytoplasmic processes of the neural crest cells project on the lateral surface of the neural tube. They have no special distribution patterns. NC: neural crest. Sclerotome cells do not yet appear. Stage 30, X 168 .

Fig. 2. A pair of scanning electron micrographs showing the lateral surface of the neural tube and the medial surface of the somites at the early migration period of the neural crest cells. The distribution pattern of the migrating neural crest cells on the lateral wall of the neural tube is random. The sclertome cells (SC) appear segmentally corresponding to the somites but at this stage their dorsal edges do not reach the neural tube yet. Stage $31, \times 168$. 

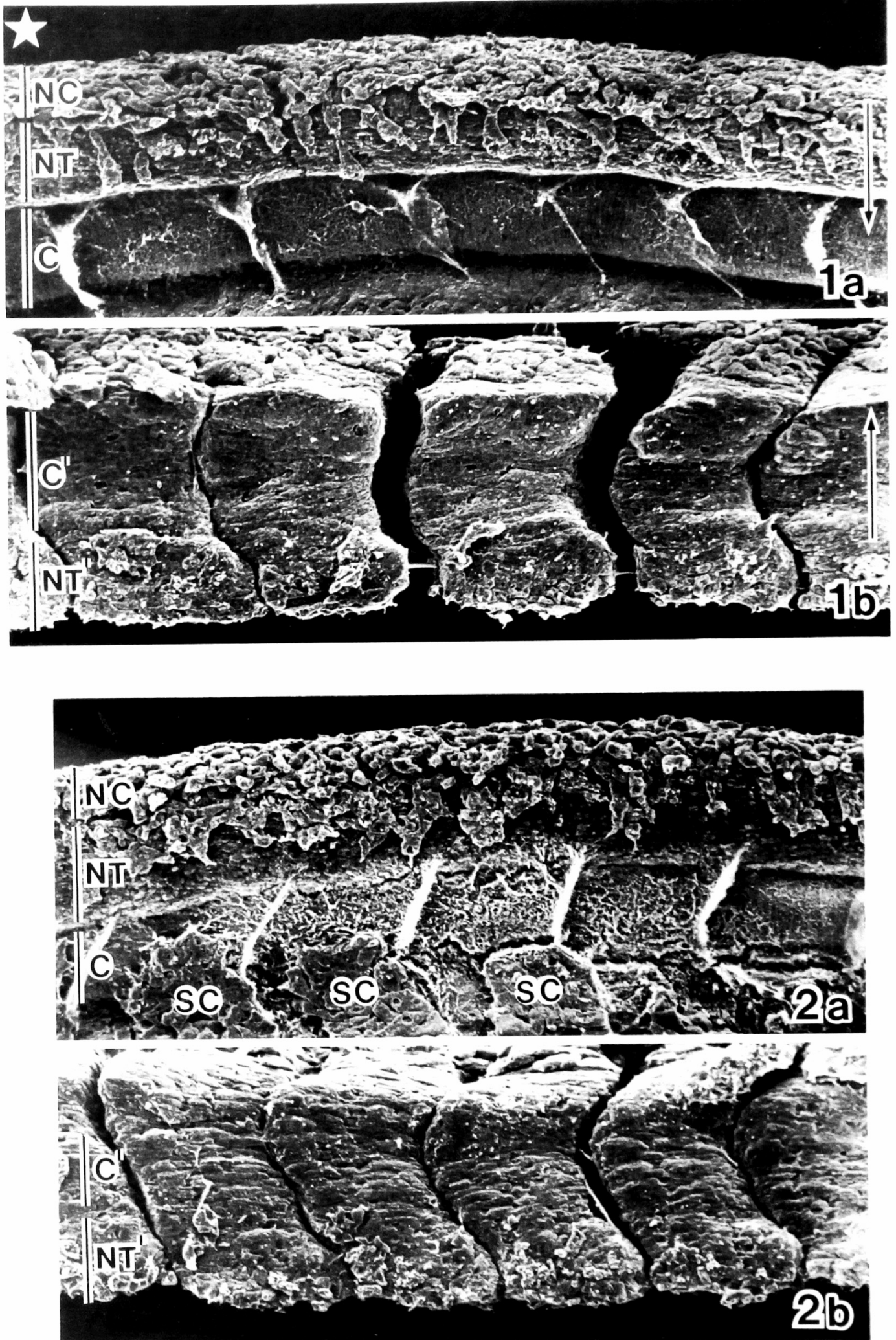


\section{Plate II}

Fig. 3. A pair of scanning electron micrographs showing the sclerotome cells(SC) reaching the NT'zone. $\mathrm{b}$ : Most of the neural crest cells and the sclerotome cells distribute on the medial surface of the somites. In the NT'zone, a cell group corresponding to a somite can be seen. Each group is connected to each other(arrows). It is difficult to distinguish the neural crest cells from the sclerotome cells but the cells in the NT' $z$ one are probably the neural crest cells and smaller than the sclerotome cells. Stage 31 , $\times 168$.

Fig. 4. A pair of scanning electron micrographs showing a continuous cell sheet in the space between the neural tube and the somites. b: Most of the cells distribute on the medial surface of the somites and form a thick cell layer. In this layer it is difficult to distinguish the neural crest cells and the sclerotome cells. Stage $35, \times 168$. 

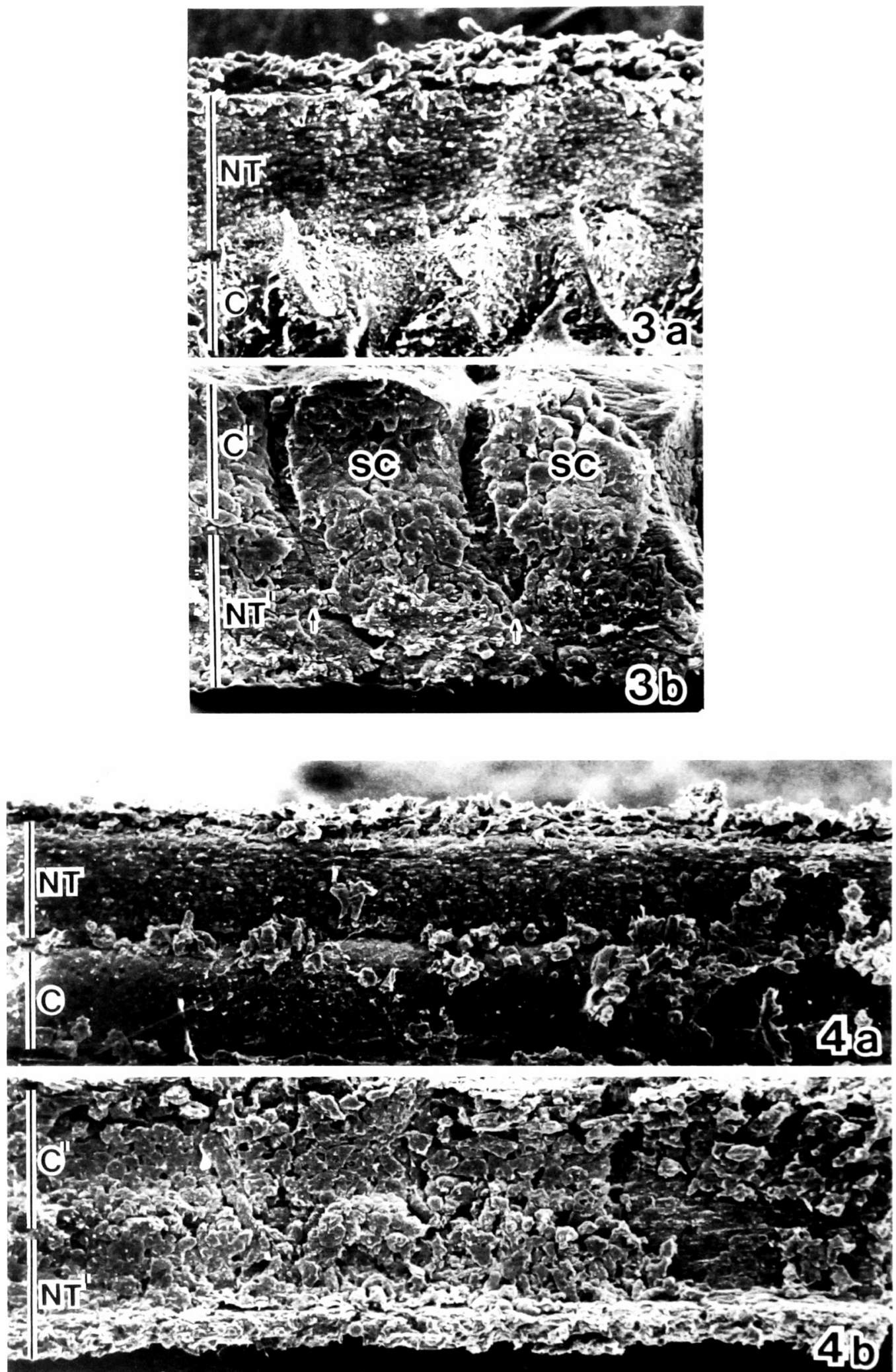
S. Hirano and T. Shirai

\section{Plate III}

Fig. 5. The lateral view of the neural tube and the notochord. a: Three primordia of the spinal ganglia (Large arrows) can be seen on the lateral wall of the neural tube. $b$ : The middle portion of the spinal ganglion (SPG) is enlarged. It is difficult to distinguish the cells in the spinal ganglion from its surrounding cells by their size and shape. Small arrow: The ventral root of the spinal nerve. Stage 36 , a: $\times 170, b: \times 400$. 

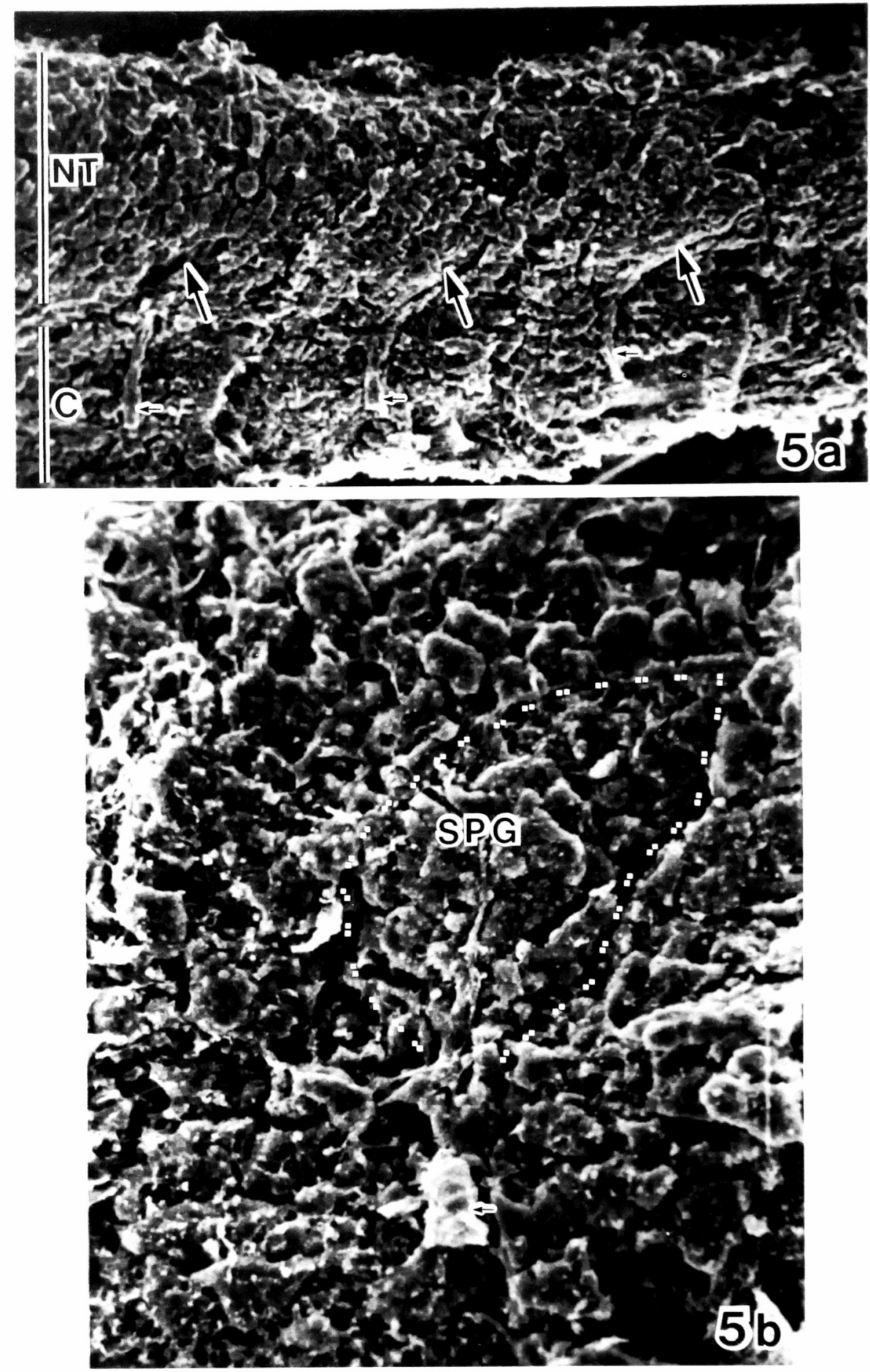


\section{Plate IV}

Fig. 6. The lateral view of a spinal ganglion (SPG) and the sclerotome cells (SC). A newly formed spinal ganglion can be clearly seen on the medial surface of a myotome (M) (compared with Fig. 5.). The ventral root is covered by the cells(arrows). Stage $40, \times 540$

Fig. 7. A pair of scanning electron micrographs showing three vertebral arches (arrow heads) on the lateral surface of the neural tube(a) and three spinal ganglia (arrows) on the medial surface of the myotomes(b). The spinal ganglia are solid and their surface is smooth. Stage $45, \times 180$. 

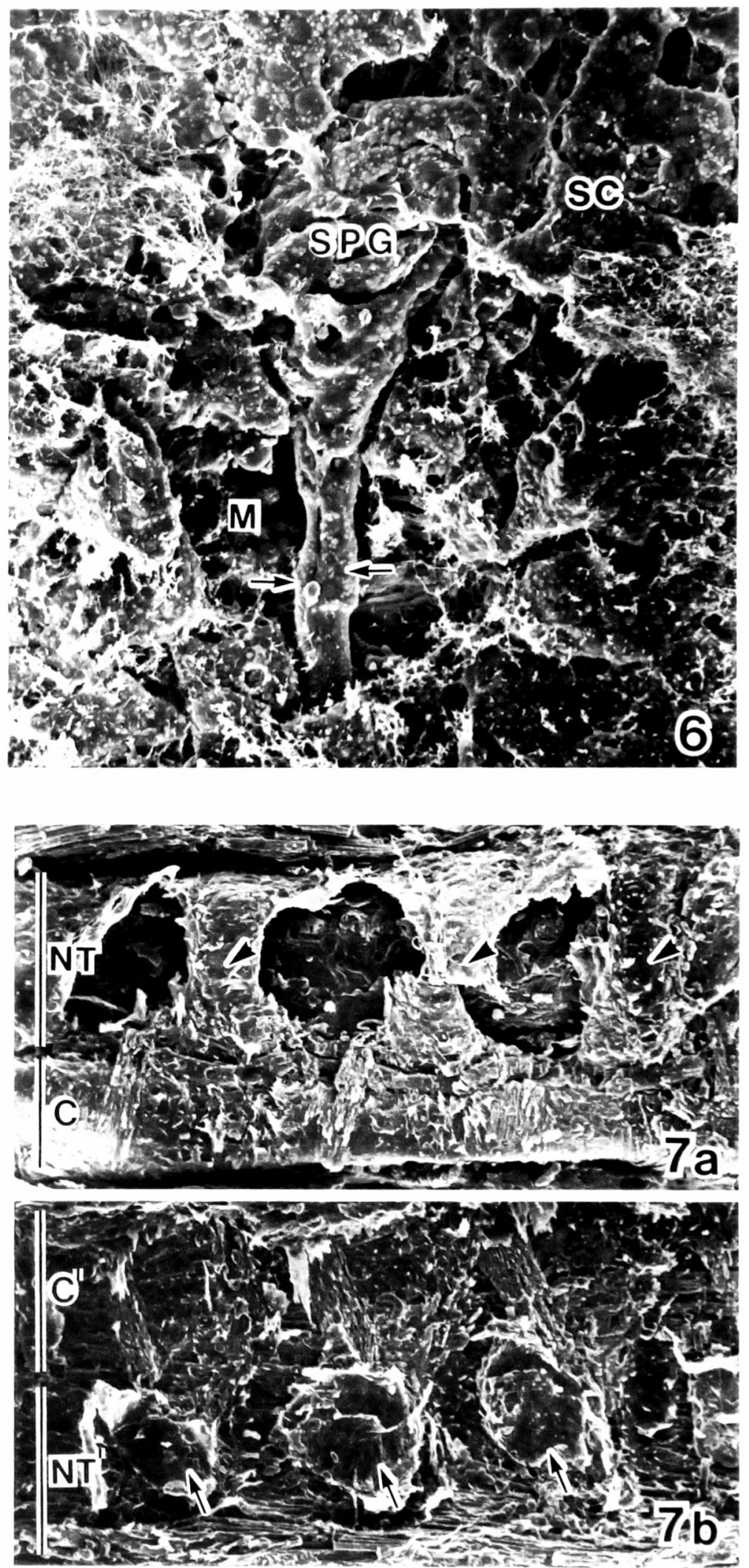